\title{
Oxidation of $\mathrm{Fe}_{1-x} \mathrm{~S}$ Pellet
}

\author{
By Zenjiro Asaki*, Takeshi Atsumi** and Yoshio Kondo*
}

\begin{abstract}
The oxidation of iron sulfide pellet was studied at 773 to $973 \mathrm{~K}$ in a mixed $\mathrm{O}_{2}-\mathrm{N}_{2}$ gas stream. The composition of iron sulfide was $\mathrm{Fe}_{0.90} \mathrm{~S}$ to $\mathrm{Fe}_{100} \mathrm{~S}$. The oxygen partial pressure in the gas stream was between $5.05 \times 10^{3}$ and $2.02 \times 10^{4} \mathrm{~Pa}$. The results were compared with those in the oxidation of dense plates of iron sulfide reported in a previous paper. In the oxidation of the pellet of higher sulfur activity, the pellet mass was decreased from the start of oxidation accompanied by the evolution of $\mathrm{SO}_{2}$ gas. The rate of oxidation was controlled by gas film mass transfer in the initial stage of oxidation and by gas diffusion through the outer oxide layer of the pellet in the subsequent stage. In the oxidation of the pellet of lower sulfur activity, on the other hand, the pellet mass was increased in the initial stage of oxidation, which was followed by a decrease of the mass. The evolution of $\mathrm{SO}_{2}$ gas was observed from the start of oxidation. This observation is different from that in the oxidation of dense plates of iron sulfide: no $\mathrm{SO}_{2}$ gas was evolved during the period of mass increase. It was found that the preferential oxidation of iron which resulted in a mass increase took place in the inner core of the pellet simultaneously with the oxidation of sulfide of higher sulfur activity in the outer layer of the pellet which was accompanied by the evolution of $\mathrm{SO}_{2}$ gas. It was also found that the preferential oxidation of iron in the sulfide particles of which the pellet consisted took place in a very short time. The overall rate of oxidation of the pellet was analysed by a simplified model.
\end{abstract}

(Received August 8, 1985)

Keywords: oxidation kinetics of iron sulfide, non-stoichiometric iron sulfide, oxidation of pellet, preferential oxidation, unreacted-core model, gas diffusion

\section{Introduction}

The oxidation of iron sulfide is of basic importance to understand the processes of nonferrous extractive metallurgy. It is well known, for example, that iron is preferentially oxidized in the oxidation of copper concentrate. In a previous paper ${ }^{(1)}$, dense plates of $\mathrm{FeS} 10 \mathrm{~mm}$ long, $7 \mathrm{~mm}$ wide and $3 \mathrm{~mm}$ thick were oxidized, and it was reported that iron diffused from the interior of the sulfide to the surface and it was preferentially oxidized in the earlier stage of oxidation without the evolution of $\mathrm{SO}_{2}$ gas. After the sulfur was concentrated in the inner sulfide and the sulfur activity was raised, the oxidation proceeded accompanied by the evolution of $\mathrm{SO}_{2}$ gas. It is clear from the above that the progress of oxidation of iron sulfide depends on the composition.

* Department of Metallurgy, Kyoto University, Kyoto 606, Japan.

** Graduate Student, Kyoto University. Present address: Gifu Works, Kawasaki Heavy Industries, Ltd., Kagamihara 504, Japan.
Cylindrical briquets of iron sulfide $12 \mathrm{~mm}$ in diameter and about $15 \mathrm{~mm}$ high were oxidized in an air stream at 573 to $1173 \mathrm{~K}$ by Henderson $^{(2)}$. It was found from the experiments using the briquets of different voids from 24.5 to $31.2 \%$ that the overall rate of oxidation was controlled by the gas diffusion through the porous oxide layer. However, the sulfur content of the iron sulfide used in his experiments was 28.1 mass \% which was considerably lower than the stoichiometric composition of 36.5 mass $\% \mathrm{~S}$, and the sample contained metallic iron. It is supposed for this reason that the detailed mechanism of oxidation may be more complicated.

Pellet consists of fine particles and the gas diffusion through pores between particles plays an important role in the overall rate of oxidation. It was intended in the present work to study the oxidation of iron sulfide pellet and to compare the results with those in the oxidation of dense plates of iron sulfide reported in the previous paper ${ }^{(1)}$. The composition of iron sulfide was varied from $\mathrm{Fe}_{0.90} \mathrm{~S}$ to $\mathrm{Fe}_{1.00} \mathrm{~S}$. In order to facilitate to estimate the rate of gas 
diffusion in the pellet, measurements of particle size distribution of iron sulfide with which the pellet was prepared and of pore size distribution of the pellet were also carried out.

\section{Experimental}

Iron sulfide was prepared from iron powder of $99.99 \%$ purity and sulfur powder of 99.999\% purity. The weighed amount of the powder mixture was heated in an evacuated quartz tube at $523 \mathrm{~K}$ for 3 days and subsequently at $1173 \mathrm{~K}$ for $18 \mathrm{ks}$. The composition of iron sulfide was chosen at $\mathrm{Fe}_{0.90} \mathrm{~S}, \mathrm{Fe}_{0.94} \mathrm{~S}$ and $\mathrm{Fe}_{1.00} \mathrm{~S}$. The resulting iron sulfide was ground to minus 150 mesh size, and the size distribution was measured by an Andreason pipette. The measured particle size distribution was between 5 and $40 \mu \mathrm{m}$, and the mean particle diameter was $17.4 \mu \mathrm{m}$.

The obtained iron sulfide particles were pressed into a briquet $11 \mathrm{~mm}$ in diameter and ca. $10 \mathrm{~mm}$ high at a pressure of $196 \mathrm{MPa}$, and it was cut into a spherical pellet. The diameter of the pellet was measured in three different directions at right angles with one another. The mean diameter of the pellet, $d$, was listed in Table 1 together with the experimental conditions. The porosity of the pellets, $\varepsilon$, was calculated from the mass and the diameter of pellet and is also listed in Table 1. The density of iron sulfide was taken as $4.79 \times 10^{6} \mathrm{~g} \cdot \mathrm{m}^{-3(5)}$.
The experimental apparatus and the procedure were described in a previous $\operatorname{paper}^{(4)}$; an iron sulfide pellet was placed on a platinum net and heated in a quartz reaction tube of $30 \mathrm{~mm}$ ID in which nitrogen gas was sent at a flow rate of $1.5 \times 10^{-5} \mathrm{~m}^{3} \cdot \mathrm{s}^{-1}$. The nitrogen gas flow was switched to the mixed $\mathrm{O}_{2}-\mathrm{N}_{2}$ gas flow of the same flow rate, and the oxidation was started. The oxygen partial pressure in the mixed $\mathrm{O}_{2}-\mathrm{N}_{2}$ gas was varied between $5.05 \times 10^{3}$ and $2.02 \times 10^{4} \mathrm{~Pa}$. The mass change of the sulfide pellet was continuously measured during the oxidation by a Shimadzu automatic microbalance RMB-50, and the $\mathrm{SO}_{2}$ concentration in the exit gas from the reaction tube was measured by a Shimadzu infrared gas analyser URA-2S.

\section{Results}

The time variations of the sample mass and the $\mathrm{SO}_{2}$ concentration in the exit gas are shown in Figs. 1 to 4 . The sample mass shown in these figures is the value per unit surface area of the pellet, because the pellet diameter was of some variety, as shown in Table 1 .

As seen in Figs. 1 and 2, a good agreement was obtained between the repeated measurements of sample mass in the same experimental conditions. It is seen in Fig. 1 that in the oxidation of $\mathrm{Fe}_{0.90} \mathrm{~S}$ pellet at $773 \mathrm{~K}$, a very slight increase of sample mass was observ-

Table 1 Experimental conditions.

\begin{tabular}{|c|c|c|c|c|c|c|}
\hline Run & $(1-x)$ & $\begin{array}{c}p_{\mathrm{O}_{2}} \times 10^{-4} \\
(\mathrm{~Pa})\end{array}$ & $\begin{array}{c}\text { Temperature } \\
(\mathrm{K})\end{array}$ & $\begin{array}{l}w_{0} \\
(\mathrm{~g})\end{array}$ & $\begin{array}{c}d \times 10^{3} \\
(\mathrm{~m})\end{array}$ & $(\stackrel{\varepsilon}{-)})$ \\
\hline 1 & 0.90 & 2.02 & 873 & 0.9826 & 8.25 & 0.304 \\
\hline 2 & $"$ & $"$ & 973 & 0.7899 & 7.80 & 0.338 \\
\hline 3 & " & " & 773 & 1.0051 & 8.43 & 0.332 \\
\hline 4 & 0.94 & $\prime \prime$ & 873 & 0.7665 & 7.78 & 0.352 \\
\hline 5 & $"$ & $"$ & 973 & 1.5912 & 9.45 & 0.250 \\
\hline 6 & $"$ & $"$ & 873 & 0.4627 & 6.32 & 0.270 \\
\hline 7 & 0.90 & " & 873 & 1.5270 & 9.62 & 0.317 \\
\hline 8 & 1.00 & $"$ & 873 & 0.9093 & 8.02 & 0.298 \\
\hline 9 & " & " & 973 & 1.5528 & 9.57 & 0.295 \\
\hline 10 & 0.94 & $"$ & 773 & 1.1583 & 8.62 & 0.280 \\
\hline 11 & 1.00 & $" \prime$ & 773 & 1.2909 & 9.07 & 0.311 \\
\hline 12 & $" 1$ & $" \prime$ & 973 & 1.1950 & 8.78 & 0.297 \\
\hline 13 & 0.90 & $" \prime$ & 773 & 1.0758 & 8.25 & 0.237 \\
\hline 14 & 1.00 & 1.01 & 773 & 1.2382 & 8.93 & 0.308 \\
\hline 15 & " & 0.51 & 773 & 1.2393 & 8.67 & 0.243 \\
\hline
\end{tabular}




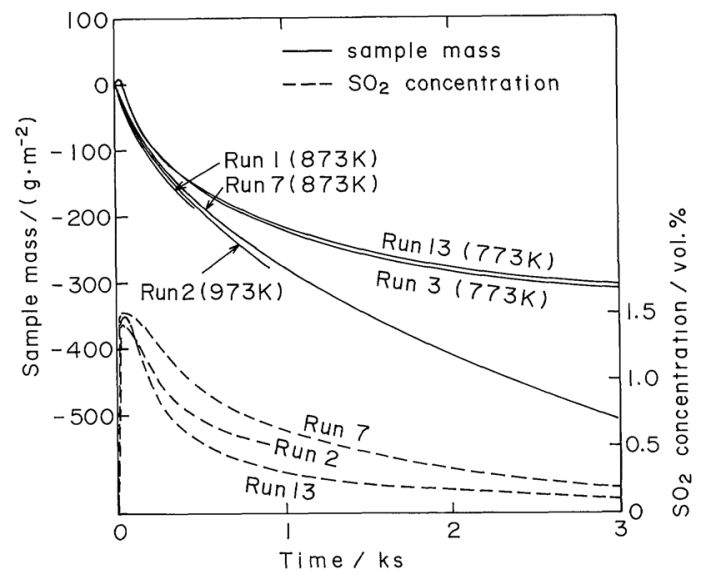

Fig. 1 Mass change of sample and $\mathrm{SO}_{2}$ concentration in exit gas $\left(\mathrm{Fe}_{0.90} \mathrm{~S}\right.$ and $\left.p_{\mathrm{O}_{2}}=2.02 \times 10^{4} \mathrm{~Pa}\right)$.

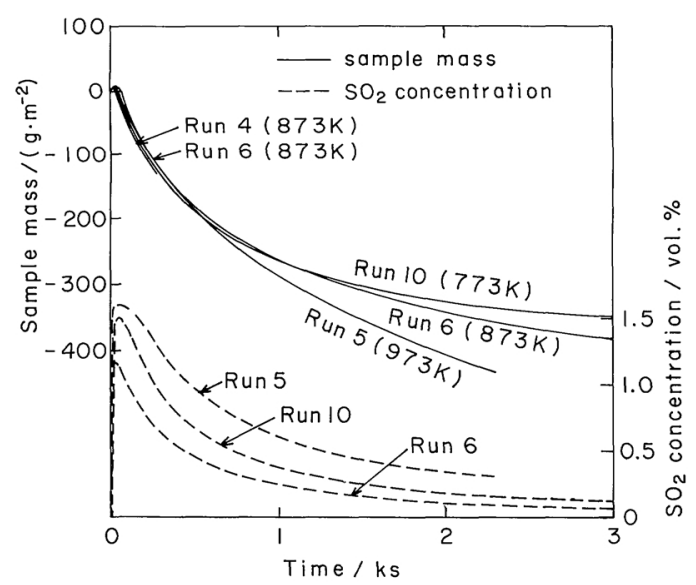

Fig. 2 Mass change of sample and $\mathrm{SO}_{2}$ concentration in exit gas $\left(\mathrm{Fe}_{0.94} \mathrm{~S}\right.$ and $\left.p_{\mathrm{O}_{2}}=2.02 \times 10^{4} \mathrm{~Pa}\right)$.

ed at the start of oxidation, which was followed by the decrease. At the temperatures of 873 and $973 \mathrm{~K}$, on the other hand, the sample mass was decreased from the start of oxidation. A relatively large amount of $\mathrm{SO}_{2}$ gas was evolved in the initial stage of oxidation, and the $\mathrm{SO}_{2}$ concentration was decreased with the reaction time. The effect of temperature on the $\mathrm{SO}_{2}$ concentration was not evident.

It is seen in Fig. 2 that a slight increase of the sample mass was observed at the start of oxidation at each experimental temperature of 773 , 873 and $973 \mathrm{~K}$ in the oxidation of $\mathrm{Fe}_{0.94} \mathrm{~S}$ pellet. Further marked mass increase was observed at the start of oxidation of $\mathrm{Fe}_{1.00} \mathrm{~S}$ pellets, as shown in Fig. 3.

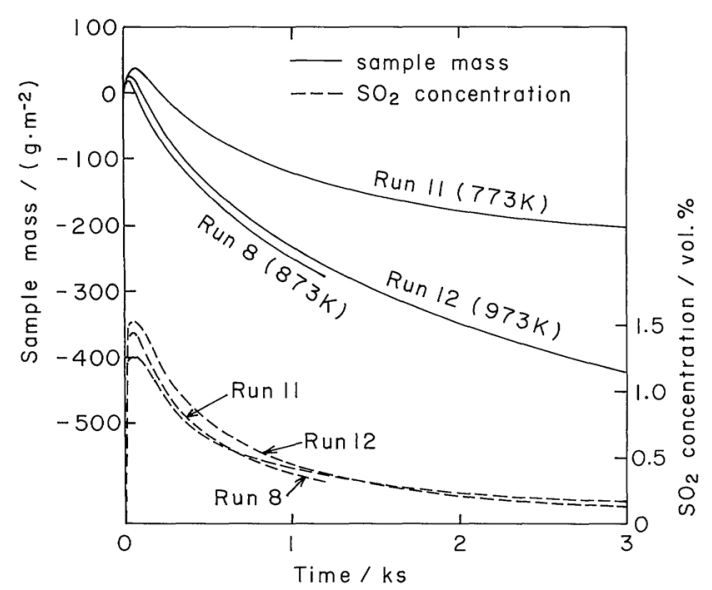

Fig. 3 Mass change of sample and $\mathrm{SO}_{2}$ concentration in exit gas $\left(\mathrm{Fe}_{1.00} \mathrm{~S}\right.$ and $\left.p_{\mathrm{O}_{2}}=2.02 \times 10^{4} \mathrm{~Pa}\right)$.

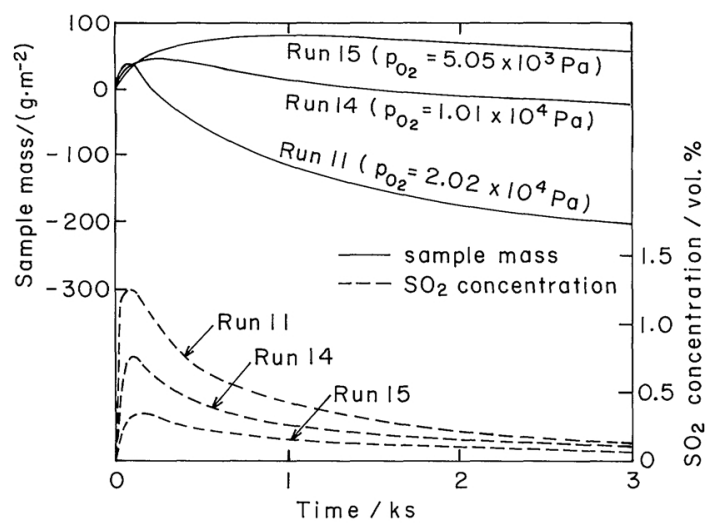

Fig. 4 Mass change of sample and $\mathrm{SO}_{2}$ concentration in exit gas $\left(\mathrm{Fe}_{1.00} \mathrm{~S}\right.$ and $\left.773 \mathrm{~K}\right)$.

Figure 4 shows the variations of the sample mass and the $\mathrm{SO}_{2}$ concentration with the oxygen partial pressure at $773 \mathrm{~K}$. The composition of iron sulfide was $\mathrm{Fe}_{1.00} \mathrm{~S}$. When $p_{\mathrm{O}_{2}}$ was $2.02 \times 10^{4} \mathrm{~Pa}$, the sample mass was increased in the initial $100 \mathrm{~s}$, which was followed by a decrease. At lower $p_{\mathrm{O}_{2}}$ of $1.01 \times 10^{4}$ and $5.05 \times 10^{3} \mathrm{~Pa}$, the sample mass continued to increase for $200 \mathrm{~s}$ and $1 \mathrm{ks}$, respectively. The $\mathrm{SO}_{2}$ concentration was decreased at lower $p_{\mathrm{O}_{2}}$. It was also noted that an appreciable amount of $\mathrm{SO}_{2}$ gas was evolved during the period of mass increase.

The cross section of the pellet oxidized at $873 \mathrm{~K}$ for $1.26 \mathrm{ks}$ (run 8) is shown in Fig. 5. As seen in this photograph, the oxidation proceed- 


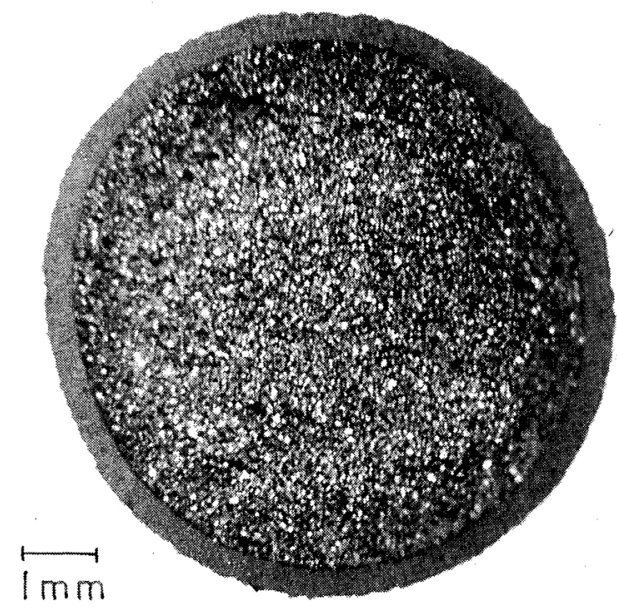

Fig. 5 Micrograph of a cross section of oxidized pellet $\left(\mathrm{Fe}_{1.00} \mathrm{~S}, 873 \mathrm{~K}\right.$ and $\left.p_{\mathrm{O}_{2}}=2.02 \times 10^{4} \mathrm{~Pa}\right)$.

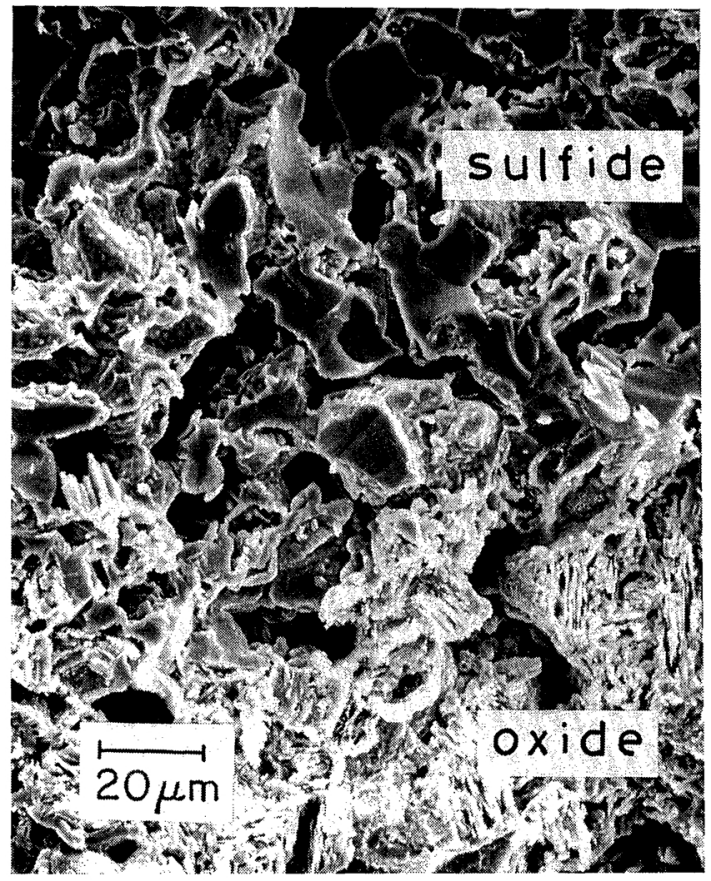

Fig. 6 Scanning electron micrograph of particles near reaction interface $\left(\mathrm{Fe}_{1.00} \mathrm{~S}, 873 \mathrm{~K}\right.$ and $\left.p_{\mathrm{O}_{2}}=2.02 \times 10^{4} \mathrm{~Pa}\right)$.

ed inward from the pellet surface. From a scanning microscopic observation of the particles near the reaction interface shown in Fig. 6, it was revealed that the sulfide particles adjacent to the interface were scarcely oxidized, in- dicating that the unreacted-core model can be applied to the analysis of the progress of oxidation.

Powder X-ray diffraction patterns of $\mathrm{Fe}_{1.00} \mathrm{~S}$ pellets oxidized at 773 and $973 \mathrm{~K}$ showed that the oxidized product was $\mathrm{Fe}_{2} \mathrm{O}_{3}$ with a very small amount of $\mathrm{Fe}_{3} \mathrm{O}_{4}$. It was also found that the composition of the inner sulfide core was shifted to $\mathrm{Fe}_{0.90} \mathrm{~S}$ to $\mathrm{Fe}_{0.88} \mathrm{~S}$ due to the oxidation.

\section{Discussion}

\section{Progress of the oxidation}

It was mentioned above that the sample mass was increased at the start of oxidation and subsequently decreased. The reaction of mass increase may be written as follows:

$$
\begin{aligned}
& \mathrm{Fe}_{1-x} \mathrm{~S}=\mathrm{Fe}_{1-x-x^{\prime}} \mathrm{S}+x^{\prime} \mathrm{Fe} . \\
& x^{\prime} \mathrm{Fe}+\frac{2 x^{\prime}}{3} \mathrm{O}_{2}=\frac{x^{\prime}}{3} \mathrm{Fe}_{3} \mathrm{O}_{4} . \\
& \frac{x^{\prime}}{3} \mathrm{Fe}_{3} \mathrm{O}_{4}+\frac{x^{\prime}}{12} \mathrm{O}_{2}=\frac{x^{\prime}}{2} \mathrm{Fe}_{2} \mathrm{O}_{3} .
\end{aligned}
$$

The reaction mechanism was considered in the previous paper ${ }^{(1)}$ : iron diffuses from the inner sulfide core outward to the surface, and it is oxidized to form oxide. No $\mathrm{SO}_{2}$ gas is evolved in these reactions. The reaction of mass decrease may be written as follows:

$$
\begin{aligned}
& \mathrm{Fe}_{1-x} \mathrm{~S}+\frac{5-2 x}{3} \mathrm{O}_{2}=\frac{1-x}{3} \mathrm{Fe}_{3} \mathrm{O}_{4}+\mathrm{SO}_{2} . \\
& \frac{1-x}{3} \mathrm{Fe}_{3} \mathrm{O}_{4}+\frac{1-x}{12} \mathrm{O}_{2}=\frac{1-x}{2} \mathrm{Fe}_{2} \mathrm{O}_{3} .
\end{aligned}
$$

In order to examine the feasibilities of the reactions (1) and (2) and of the reaction (4), $\mathrm{SO}_{2}$ partial pressure in equilibrium with $\mathrm{Fe}_{1-x} \mathrm{~S}$ and $\mathrm{Fe}_{3} \mathrm{O}_{4}$ is calculated ${ }^{(1)(4)}$. The equilibrium $\mathrm{S}_{2}$ pressure of $\mathrm{Fe}_{1-x} \mathrm{~S}$ needed for this calculation was taken from the data summarized by Burgmann et $a l .{ }^{(3)}$ The calculated results are shown in Fig. 7. The experimental conditions in which the sample mass was decreased from the start of oxidation are shown by open circles, and those of mass increase at the initial stage of oxidation are shown by closed circles. 


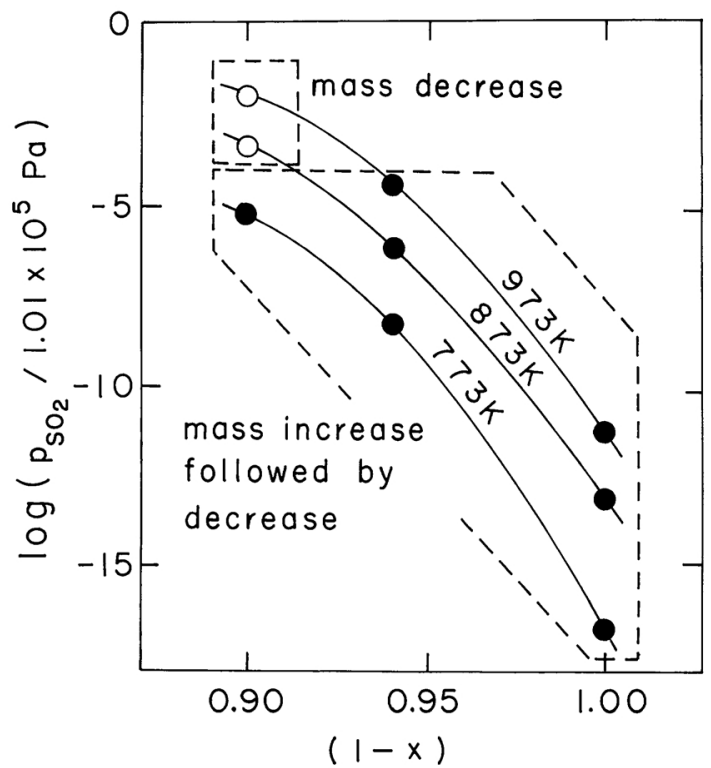

Fig. 7 Partial pressure of $\mathrm{SO}_{2}$ gas in equilibrium with $\mathrm{Fe}_{1-x} \mathrm{~S}$ and $\mathrm{Fe}_{3} \mathrm{O}_{4}$.

As seen in this figure, the progress of reaction (4) is feasible, when $p_{\mathrm{SO}_{2}}$ is higher than about $40 \mathrm{~Pa}$. This is because successive removal of $\mathrm{SO}_{2}$ gas from the reaction interface is necessary for the successive progress of reaction (4). When the $p_{\mathrm{SO}_{2}}$ is higher, the rate of mass transfer of $\mathrm{SO}_{2}$ from the reaction interface to the surrounding becomes higher, resulting in the progress of reaction (4). At lower $p_{\mathrm{SO}_{2}}$, iron is preferentially oxidized according to the reactions (1) and (2), and sulfur is concentrated in the inner sulfide.

As seen in Fig. 4, an appreciable amount of $\mathrm{SO}_{2}$ gas was evolved from the start of oxidation while the sample mass was increased, indicating that the reactions (1) to (3) and the reactions (4) and (5) took place simultaneously in the pellet. This observation is different from that in the previous work ${ }^{(1)}$ : no $\mathrm{SO}_{2}$ gas was evolved during the period of mass increase in the oxidation of dence plates of iron sulfide. The reason for this difference is considered as follows. The pellet consisted of fine particles whose mean diameter was $17.4 \mu \mathrm{m}$, as mentioned above. It is intended to calculate the time required for the conversion of a single $\mathrm{Fe}_{1.00} \mathrm{~S}$ particle to an $\mathrm{Fe}_{0.90} \mathrm{~S}$ particle due to the reactions (1) to (3) at $873 \mathrm{~K}$ on the assumption that the reaction rate is controlled by the iron diffusion in the sulfide ${ }^{(1)}$.

With an approximation that the sulfide particle is regarded as a sphere of radius $r_{0}$, the diffusion of iron is represented by

$$
\frac{\partial c_{\mathrm{Fe}}}{\partial t}=\frac{\partial}{\partial r}\left(c_{\mathrm{Fe}} D_{\mathrm{Fe}}^{*} \frac{\partial \ln a_{\mathrm{Fe}}}{\partial r}\right)+\frac{2}{r} c_{\mathrm{Fe}} D_{\mathrm{Fe}}^{*} \frac{\partial \ln a_{\mathrm{Fe}}}{\partial r} .
$$

Initial and boundary conditions are

$$
\begin{aligned}
& c_{\mathrm{Fe}}=5.46 \times 10^{4} \mathrm{~mol} \cdot \mathrm{m}^{-3}\left(\mathrm{Fe}_{1.00} \mathrm{~S}\right) \text { at } t=0, \\
& c_{\mathrm{Fe}}=4.91 \times 10^{4} \mathrm{~mol} \cdot \mathrm{m}^{-3}\left(\mathrm{Fe}_{0.90} \mathrm{~S}\right) \text { at } r=r_{0}
\end{aligned}
$$

and

$$
\frac{\partial c_{\mathrm{Fe}}}{\partial r}=0 \quad \text { at } \quad r=0 .
$$

The iron concentration, $c_{\mathrm{Fe}}$, in $\mathrm{Fe}_{1.00} \mathrm{~S}$ was calculated from the density of $4.79 \times 10^{6} \mathrm{~g} \cdot \mathrm{m}^{-3}$ obtained by Haraldsen ${ }^{(5)}$. The $c_{\mathrm{Fe}}$ in $\mathrm{Fe}_{0.90} \mathrm{~S}$ was estimated from the above density neglecting the variation of molar volume with the composition. The iron activity, $a_{\mathrm{Fe}}$, was calculated from the $p_{\mathrm{S}_{2}}$-values obtained by Burgmann et $a l . .^{(3)}$ and Turkdogan ${ }^{(6)}$ using Gibbs-Duhem equation. The self-diffusivity of iron in iron sulfide, $D_{\mathrm{Fe}}^{*}$, was estimated from the data obtained by Turkdogan ${ }^{(6)}$ and Condit ${ }^{(7)}$, and it was approximated by the following expression.

$$
D_{\mathrm{Fe}}^{*}=5.95 \times 10^{-11}\left(1-\frac{N_{\mathrm{Fe}}}{N_{\mathrm{s}}}\right) \text { at } 873 \mathrm{~K} \text {. }
$$

Equation (6) was numerically solved using the above values of parameters.

Taking $x$ and $x^{\prime}$ in eqs. (1) to (3) as 0 and 0.1 , respectively, the overall reaction is written as

$$
\mathrm{FeS}+0.075 \mathrm{O}_{2}=\mathrm{Fe}_{0.90} \mathrm{~S}+0.05 \mathrm{Fe}_{2} \mathrm{O}_{3} .
$$

When an $\mathrm{Fe}_{1.00} \mathrm{~S}$ particle of $r_{0}=8.7 \mu \mathrm{m}$ is converted to $\mathrm{Fe}_{0.90} \mathrm{~S}$ obeying the reaction (8), a mass increase of $3.61 \times 10^{-9} \mathrm{~g}$ accompanies. The rate of mass increase of a sulfide particle is given by

$$
\frac{d \Delta w}{d t}=-\left.0.75 M_{\mathrm{O}_{2}} \cdot 4 \pi r_{0}^{2} c_{\mathrm{Fe}} D_{\mathrm{Fe}}^{*} \frac{\partial \ln a_{\mathrm{Fe}}}{\partial r}\right|_{r=r_{0}} .
$$


Time required for a $90 \%$ mass increase of the above value of a particle is calculated from eq. (9) to be $0.07 \mathrm{~s}$ at $873 \mathrm{~K}$. Similar calculations under other experimental conditions including the oxidation of $\mathrm{Fe}_{1.00} \mathrm{~S}$ and $\mathrm{Fe}_{0.94} \mathrm{~S}$ pellets at 873 and $973 \mathrm{~K}$ showed that the particle composition converted to $\mathrm{Fe}_{0.90} \mathrm{~S}$, at which composition the preferential oxidation of iron was not observed at these temperatures, in a very short time.

It can be said from the above that the sulfide particles on the pellet surface are converted from $\mathrm{Fe}_{1.00} \mathrm{~S}$ or $\mathrm{Fe}_{0.94} \mathrm{~S}$ to $\mathrm{Fe}_{0.90} \mathrm{~S}$ due to the preferential oxidation of iron in an instant and that the reactions (4) and (5) take place on the pellet surface at the subsequent stage while the reactions (1) to (3) continue to take place in the inner sulfide cores. This may be a reason why $\mathrm{SO}_{2}$ gas is evolved from the start of oxidation which is accompanied by the mass increase.

\section{Rate of mass increase of pellet}

In the oxidation of $\mathrm{Fe}_{1.00} \mathrm{~S}$ pellet, the pellet mass was evidently increased at the initial stage of oxidation, as shown in Figs. 3 and 4. The mass increase and $\mathrm{SO}_{2}$ concentration in the exit gas in the initial $60 \mathrm{~s}$ are again illustrated in Fig. 8. As seen in this figure, the temperature

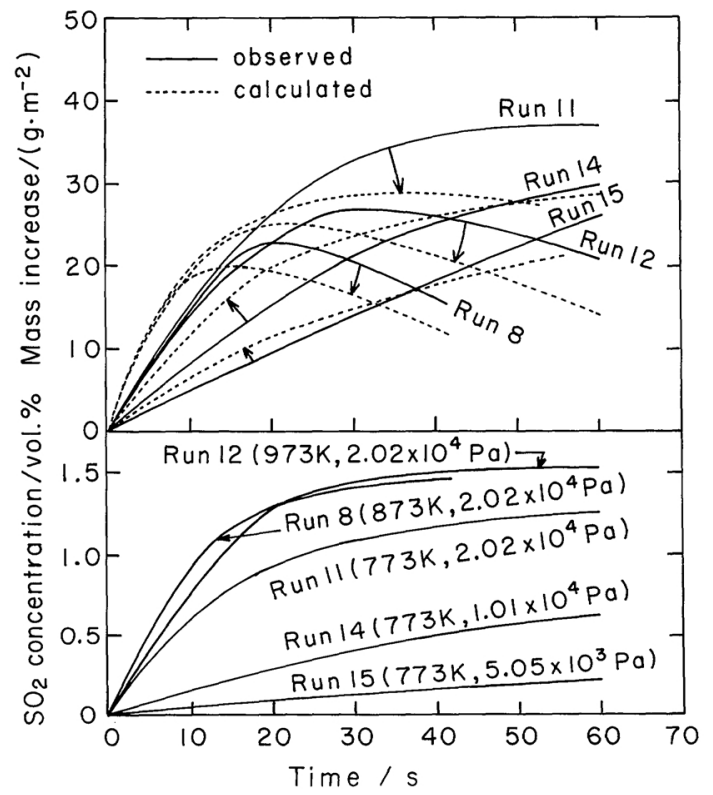

Fig. 8 Mass increase and $\mathrm{SO}_{2}$ concentration in exit gas at initial stage of oxidation of $\mathrm{Fe}_{1.00} \mathrm{~S}$ pellets.

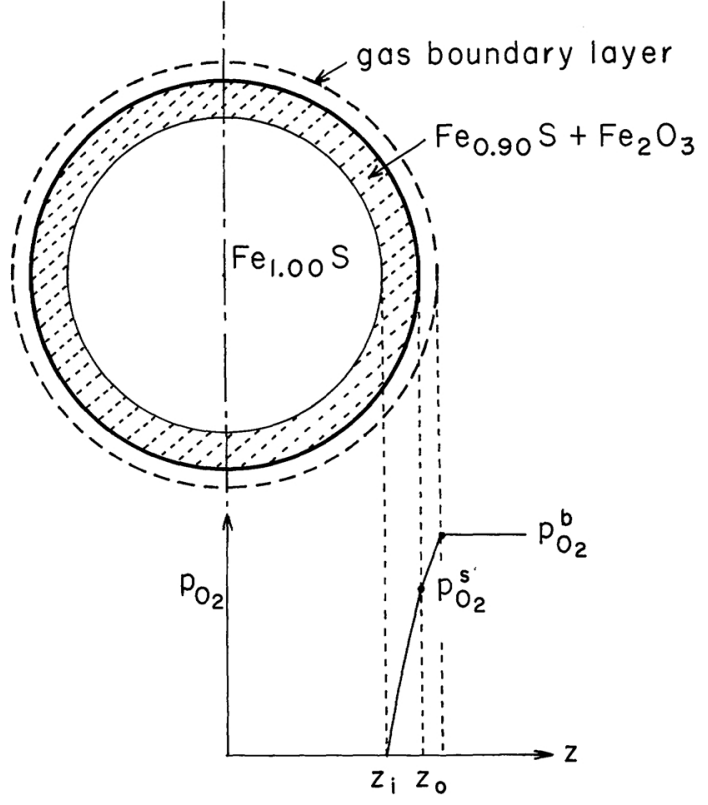

Fig. 9 A model for mass increase in oxidation of $\mathrm{Fe}_{1.00} \mathrm{~S}$ pellets.

variation of mass increase is minor in the initial $20 \mathrm{~s}$, and it is markedly affected by the oxygen partial pressure. The $\mathrm{SO}_{2}$ concentration is also decreased at lower $p_{\mathrm{O}_{2}}$. Then it is supposed that the rate of reaction of mass increase is affected by the duffusional process of oxygen.

It was already mentioned that the reaction (8) took place in sulfide particles within a very short time of about $0.07 \mathrm{~s}$. Then a simplified model schematically illustrated in Fig. 9 was proposed to investigate the rate of mass increase. The reaction (8) takes place at an interface of radius $z_{i}$, and the rate of this reaction is determined by the rate of oxygen diffusion to the interface. Subsequently, the reaction,

$$
\mathrm{Fe}_{0.90} \mathrm{~S}+1.675 \mathrm{O}_{2}=0.45 \mathrm{Fe}_{2} \mathrm{O}_{3}+\mathrm{SO}_{2},
$$

takes place in the shell from $z_{\mathrm{i}}$ to $z_{0}$.

It is thought, however, that a dense $\mathrm{Fe}_{2} \mathrm{O}_{3}$ film is formed on the particle surface due to the reaction (8) and the oxygen diffuses through cracks of the dense $\mathrm{Fe}_{2} \mathrm{O}_{3}$ film, which causes the reaction (10) to occur at the subsequent state $^{(1)}$. Consequently the analysis of the rate of reaction (10) is relatively complicated, and the progress of reaction (10) was estimated from the observed $\mathrm{SO}_{2}$ concentration in the 
following calculation.

Assuming a quasi-steady state, diffusion of oxygen in the pellet is represented by

$$
\frac{D_{\mathrm{e}}}{R T}\left(\frac{d^{2} p_{\mathrm{O}_{2}}}{d z^{2}}+\frac{2}{z} \frac{d p_{\mathrm{O}_{2}}}{d z}\right)-n_{\mathrm{O}_{2}}=0,
$$

where $n_{\mathrm{O}_{2}}$ is the number of moles of oxygen consumed due to the reaction (10) per unit time and unit volume of the pellet, and $n_{\mathrm{O}_{2}}$ was assumed to be uniform throughout the shell between $z_{\mathrm{i}}$ and $z_{0}$. Boundary conditions for eq. (11) are

$$
D_{\mathrm{e}} \frac{d p_{\mathrm{O}_{2}}}{d z}=k_{\mathrm{g}}\left(p_{\mathrm{O}_{2}}^{\mathrm{b}}-p_{\mathrm{O}_{2}}^{\mathrm{s}}\right) \quad \text { at } \quad z=z_{0}
$$

and

$$
p_{\mathrm{O}_{2}}=0 \text { at } z=z_{1} \text {. }
$$

In the above boundary condition (13), $p_{\mathrm{O}_{2}}$ was approximated to zero, because the reaction (8) was assumed to be of diffusion control of oxygen and the equilibrium $p_{\mathrm{O}_{2}}$ of this reaction was also assumed to be low enough. Solution of eq. (11) is given by

$$
p_{\mathrm{O}_{2}}=\frac{n_{\mathrm{O}_{2}} R T}{6 D_{\mathrm{e}}}\left(z^{2}-z_{1}^{2}\right)-z_{0}^{2}\left(\frac{1}{z_{\mathrm{i}}}-\frac{1}{z}\right) A,
$$

where

$$
A=\frac{n_{\mathrm{O}_{2}} R T z_{0}}{3 D_{\mathrm{e}}}-\frac{k_{\mathrm{g}}}{D_{\mathrm{e}}}\left\{p_{\mathrm{O}_{2}}^{\mathrm{b}}-\frac{\frac{n_{\mathrm{O}_{2}} R T}{6}\left(z_{0}^{2}-z_{\mathrm{i}}^{2}\right)-z_{0}\left(\frac{z_{0}}{z_{\mathrm{i}}}-1\right)\left(\frac{n_{\mathrm{O}_{2}} R T z_{0}}{3}-k_{\mathrm{g}} p_{\mathrm{O}_{2}}^{\mathrm{b}}\right)}{D_{\mathrm{e}}+k_{\mathrm{g}} z_{0}\left(\frac{z_{0}}{z_{1}}-1\right)}\right\} .
$$

The $n_{\mathrm{O}_{2}}$ was estimated by

$$
n_{\mathrm{O}_{2}}=\frac{0.01675 v c_{\mathrm{SO}_{2}}}{(4 / 3) \pi\left(z_{0}^{3}-z_{\mathrm{i}}^{3}\right) R T},
$$

where $c_{\mathrm{SO}_{2}}$ was the observed $\mathrm{SO}_{2}$ concentration.

The rate of oxygen diffusion to the inteface is given by

$$
\begin{aligned}
J_{\mathrm{O}_{2}\left(z=z_{1}\right)} & =\left.4 \pi z_{\mathrm{i}}^{2} \frac{D_{\mathrm{e}}}{R T} \frac{d p_{\mathrm{O}_{2}}}{d z}\right|_{z=z_{1}} \\
& =4 \pi z_{\mathrm{i}}^{2} \frac{D_{\mathrm{e}}}{R T}\left(\frac{n_{\mathrm{O}_{2}} R T z_{\mathrm{i}}}{3 D_{\mathrm{e}}}-\frac{z_{0}^{2}}{z_{\mathrm{i}}^{2}} A\right) .
\end{aligned}
$$

The rate of mass increase due to the reaction (8) is

$$
\left(\frac{d \Delta w}{d t}\right)_{\mathrm{I}}=\frac{M_{\mathrm{O}_{2}}}{4 \pi z_{0}^{2}} J_{\mathrm{O}_{2}\left(z=z_{1}\right)},
$$

and the rate of mass decrease due to the reaction (10) is

$$
\left(\frac{d \Delta w}{d t}\right)_{\mathrm{II}}=-\frac{10.46}{4 \pi z_{0}^{2}} \frac{v c_{\mathrm{SO}_{2}}}{100 R T} .
$$

Then the mass change of the pellet is given by

$$
\frac{d \Delta w}{d t}=\left(\frac{d \Delta w}{d t}\right)_{\mathrm{I}}+\left(\frac{d \Delta w}{d t}\right)_{\mathrm{II}} .
$$

The time variation of $z_{\mathrm{i}}$ is represented as

$$
\frac{d z_{\mathrm{i}}}{d t}=-\frac{13.3 M_{\mathrm{FeS}}}{4 \pi z_{\mathrm{i}}^{2}(1-\varepsilon) \rho_{\mathrm{FeS}}} J_{\mathrm{O}_{2}\left(z=z_{1}\right)} .
$$

The time variation of the pellet mass was calculated numerically from the above equations, changing the $z_{\mathrm{i}}$-value due to eq. (21). The mass transfer coefficient, $k_{\mathrm{g}}$, was estimated from the Ranz-Marshall equation ${ }^{(8)}$,

$$
S h=2+0.6 R e^{1 / 2} S c^{1 / 3} .
$$

The effective diffusivity, $D_{\mathrm{e}}$, was calculated by the following expressions ${ }^{(9)(10)}$.

$$
\begin{aligned}
& D_{\mathrm{e}}=\varepsilon^{2} D . \\
& \frac{1}{D}=\frac{1-\left(1-\sqrt{M_{\mathrm{O}_{2}} / M_{\mathrm{N}_{2}}}\right) y_{\mathrm{O}_{2}}}{D_{\mathrm{O}_{2}}}+\frac{1}{D_{\mathrm{k}}} . \\
& D_{\mathrm{k}}=97 r_{\mathrm{e}} \sqrt{\frac{T}{M_{\mathrm{O}_{2}}}} .
\end{aligned}
$$

The porosity of the pellet, $\varepsilon$, listed in Table 1 was used in eq. (23). The mean pore radius, $r_{e}$, in eq. (25) was measured by an AMINCO mercury porosimeter to be $8.0 \times 10^{-7} \mathrm{~m}$. The molecular diffusivity of oxygen in nitrogen, $D_{\mathrm{O}_{2}}$, was estimated by Chapman-Enskog equa- 
Table 2 Effective diffusivity and mass transfer coefficient for the calculation of eq. (27).

\begin{tabular}{rcc}
\hline \hline Run & $D_{\mathrm{e}} \times 10^{6}\left(\mathrm{~m}^{2} \cdot \mathrm{s}^{-1}\right)$ & $k_{\mathrm{g}} \times 10^{2}\left(\mathrm{~m} \cdot \mathrm{s}^{-1}\right)$ \\
\hline 8 & 8.22 & 5.12 \\
11 & 7.56 & 3.83 \\
12 & 9.46 & 5.61 \\
14 & 7.36 & 3.88 \\
15 & 4.51 & 3.98 \\
\hline \hline
\end{tabular}

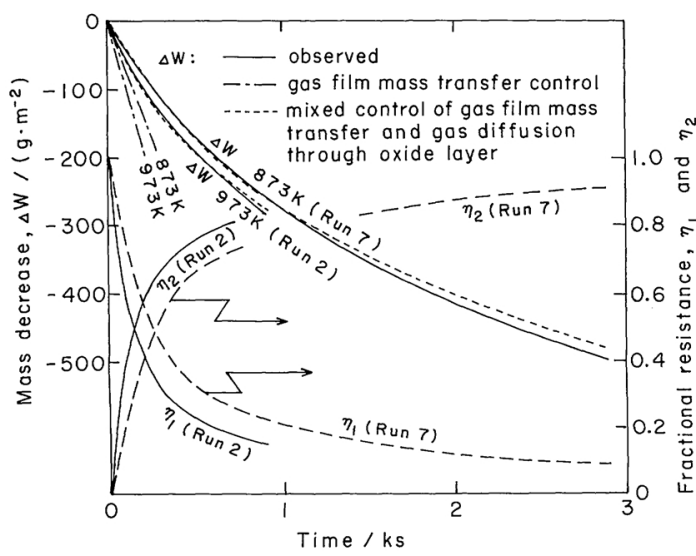

Fig. 10 Mass decrease in oxidation of $\mathrm{Fe}_{0.90} \mathrm{~S}$ pellets and fractional resistance. $\left(p_{\mathrm{O}_{2}}=2.02 \times 10^{4} \mathrm{~Pa}\right)$.

tion ${ }^{(11)}$ neglecting the effect of $\mathrm{SO}_{2}$ gas. In the calculation of $k_{\mathrm{g}}$ and $D_{\mathrm{e}}$, the density and the viscosity of gas at the reaction temperatures were used. The values of $k_{\mathrm{g}}$ and $D_{\mathrm{e}}$ thus estimated are listed in Table 2 . The calculated results of the time variation of pellet mass are shown in Fig. 8 by dotted lines. Though the calculated results were somewhat deviated from the observations, the mass increase was markedly affected by the oxygen partial pressure at the initial stage of oxidation. On the other hand, it was not evidently affected by the temperature.

\section{Rate of mass decrease of pellet}

In the oxidation of $\mathrm{Fe}_{0.90} \mathrm{~S}$ pellet, the pellet mass was decreased from the start of oxidation at 873 and $973 \mathrm{~K}$, as shown in Fig. 1. It is again illustrated in Fig. 10 by solid lines. The overall reaction is represented by eq. (10).

The initial rate of oxidation is determined by the gas film mass transfer and the chemical reaction on the pellet surface, since the oxide is not yet formed. On the assumption that the initial rate is controlled by the gas film mass transfer, the rate of mass decrease per unit surface area of the pellet is represented as

$$
\left.\frac{d \Delta W}{d t}\right|_{t=0}=-6.245 \frac{k_{\mathrm{g}}}{R T} p_{\mathrm{O}_{2}} \text {. }
$$

The mass transfer coefficient, $k_{\mathrm{g}}$, was estimated from the Ranz-Marshall equation ${ }^{(8)}$ of eq. (22) at $6.18 \times 10^{-2}$ and $4.42 \times 10^{-2} \mathrm{~m} \cdot \mathrm{s}^{-1}$ for runs 2 and 7 , respectively. The result of calculation of mass decrease are shown in Fig. 10 by dotted and dashed lines. As seen in this figure, a good agreement was obtained between the calculated and the observed initial rate of mass decrease, indicating that the resistance to the chemical reaction was negligible.

It is then assumed that the progress of reaction (10) at the subsequent stage is controlled by both the gas film mass transfer and the gas diffusion through the outer oxide layer. The inner $\mathrm{Fe}_{0.90} \mathrm{~S}$ is oxidized through $\mathrm{Fe}_{3} \mathrm{O}_{4}$ to form $\mathrm{Fe}_{2} \mathrm{O}_{3}$. However, the amount of $\mathrm{Fe}_{3} \mathrm{O}_{4}$ in the oxidized pellet is negligibly small as mentioned before, and the interface between $\mathrm{Fe}_{0.90} \mathrm{~S}$ and $\mathrm{Fe}_{2} \mathrm{O}_{3}$ is taken into account in the analysis of the rate of mass decrease. Denoting the pellet radius by $z_{0}$, the rate of mass decrease under the above assumptions is represented by

$$
\frac{d \Delta w}{d t}=-6.245 \frac{p_{\mathrm{O}_{2}}}{R T\left\{\frac{1}{k_{\mathrm{g}}}+\frac{z_{0}\left(z_{0}-z_{\mathrm{i}}\right)}{z_{\mathrm{i}} D_{\mathrm{e}}}\right\}} .
$$

The mass decrease can be correlated with the radius of interface, $z_{i}$, as

$$
\Delta w=-a\left(z_{0}^{3}-z_{\mathrm{i}}^{3}\right),
$$

where

$$
a=10.46 \frac{\left(1-\varepsilon_{\mathrm{h}}\right) \rho_{\mathrm{Fe}_{0.90} \mathrm{~S}}}{3 z_{0}^{2} M_{\mathrm{Fe}_{0.90} \mathrm{~S}}} .
$$

After substituting $z_{\mathrm{i}}$ in eq. (28) for eq. (27), integration of eq. (27) with the initial condition of $\Delta w=0$ at $t=0$ yields

$$
\begin{gathered}
\left(\frac{1}{k_{\mathrm{g}}}-\frac{z_{0}}{D_{\mathrm{e}}}\right) \Delta w+\frac{3 a z_{0}^{2}}{2 D_{\mathrm{e}}}\left(\frac{\Delta w}{a}+z_{0}^{3}\right)^{2 / 3}-\frac{3 a z_{0}^{4}}{2 D_{\mathrm{e}}} \\
=-\frac{6.245 p_{\mathrm{O}_{2}}}{R T} t .
\end{gathered}
$$


In the calculation of eq. (30), the density of $\mathrm{Fe}_{0.90} \mathrm{~S}, \quad \rho_{\mathrm{Fe}_{09} \mathrm{~S}}$, was estimated at $4.49 \times 10^{6}$ $\mathrm{g} \cdot \mathrm{m}^{-3}$ from the density of $\mathrm{Fe}_{1.00} \mathrm{~S}, 4.79 \times 10^{6}$ $\mathrm{g} \cdot \mathrm{m}^{-3}$, neglecting the variation of molar volume of pyrrhotite with the composition. In order to estimate the effective diffusivity of oxygen, $D_{\mathrm{e}}$, in eq. (30), the pore size distribution of the $\mathrm{Fe}_{2} \mathrm{O}_{3}$ layer was measured by an AMINCO mercury porosimeter, and the porosity, $\varepsilon_{\mathrm{h}}$, of 0.41 and the mean pore radius, $r_{\mathrm{e}}$, of $2.4 \times 10^{-7} \mathrm{~m}$ were obtained. These values were substituted for eqs. (23) and (25), and the mole fraction of oxygen, $y_{\mathrm{O}_{2}}$, was taken as 0.2 in eq. (24). The calculated effective diffusivity was $1.18 \times 10^{-5}$ and $1.06 \times 10^{-5} \mathrm{~m}^{2} \cdot \mathrm{s}^{-1}$ for runs 2 and 7 , respectively. In this calculation, the effect of $\mathrm{SO}_{2}$ gas was neglected.

The mass decrease calculated from eq. (30) was shown in Fig. 10 by dotted lines. As seen in this figure, the values of calculated mass decrease were in good agreement with the observed values.

From eq. (27), the fractional resistances to the gas film mass transfer, $\eta_{1}$, and the oxygen diffusion through the oxide layer, $\eta_{2}$, are represented as follows.

$$
\begin{gathered}
\eta_{1}=\frac{\frac{1}{k_{\mathrm{g}}}}{\frac{1}{k_{\mathrm{g}}}+\frac{z_{0}\left(z_{0}-z_{\mathrm{i}}\right)}{z_{\mathrm{i}} D_{\mathrm{e}}}} . \\
\eta_{2}=\frac{\frac{z_{0}\left(z_{0}-z_{\mathrm{l}}\right)}{z_{\mathrm{l}} D_{\mathrm{e}}}}{\frac{1}{k_{\mathrm{g}}}+\frac{z_{0}\left(z_{0}-z_{\mathrm{i}}\right)}{z_{\mathrm{i}} D_{\mathrm{e}}}} .
\end{gathered}
$$

The calculated $\eta_{1}$ and $\eta_{2}$ are also shown in Fig. 10. As seen in this figure, though the resistance to the gas film mass transfer is predominant at the initial stage of oxidation, the overall rate of oxidation is virtually controlled by gas diffusion through the oxide layer at the subsequent stage.

\section{Summary}

Iron sulfide of the composition of $\mathrm{Fe}_{0.90} \mathrm{~S}$, $\mathrm{Fe}_{0.94} \mathrm{~S}$ and $\mathrm{Fe}_{1.00} \mathrm{~S}$ were synthesized, and spherical pellets were made from the obtained iron sulfide particles. Mass change of the pellet and the $\mathrm{SO}_{2}$ concentration in the exit gas were continuously measured during the oxidation. The temperature was chosen between 773 and $973 \mathrm{~K}$, and the oxygen partial pressure in the mixed $\mathrm{O}_{2}-\mathrm{N}_{2}$ gas stream was varied between $5.05 \times 10^{3}$ and $2.02 \times 10^{4} \mathrm{~Pa}$. The experimental results were compared with those in the previous work $^{(1)}$, in which dense plates of $\mathrm{Fe}_{1.00} \mathrm{~S}$ were oxidized.

In the oxidation of $\mathrm{Fe}_{0.90} \mathrm{~S}$ pellet at 873 and $973 \mathrm{~K}$, the pellet mass was decreased from the start of oxidation. The oxidation proceeded from the pellet surface to the interior, and the product of oxidation was $\mathrm{Fe}_{2} \mathrm{O}_{3}$ with a very small amount of $\mathrm{Fe}_{3} \mathrm{O}_{4}$. From the analysis of the reaction rate based on the unreacted-core model, it was found that the overall rate of oxidation was controlled by the gas film mass transfer at the initial stage of oxidation and by the gas diffusion through the oxide layer at the subsequent stage.

In the oxidation of $\mathrm{Fe}_{0.94} \mathrm{~S}$ pellet, the pellet mass was slightly increased at the initial stage of oxidation, and it was decreased at the subsequent stage. In the oxidation of $\mathrm{Fe}_{1.00} \mathrm{~S}$ pellet, on the other hand, a marked mass increase was observed in the initial stage. In both cases of $\mathrm{Fe}_{0.94} \mathrm{~S}$ and $\mathrm{Fe}_{1.00} \mathrm{~S}$ pellets, an appreciable amount of $\mathrm{SO}_{2}$ gas was evolved from the start of oxidation. This observation is different from that in the previous work ${ }^{(1)}$ : no $\mathrm{SO}_{2}$ gas was evolved during the mass increase in the oxidation of dense plates of iron sulfide.

It was reported in the previous paper ${ }^{(1)}$ that the reaction of mass increase was a preferential oxidation of iron without the evolution of $\mathrm{SO}_{2}$ gas. This is due to a lower sulfur activity of iron sulfide. It was supposed from theoretical considerations that this reaction proceeded within the sulfide particles on the pellet surface in a very short time of about $0.07 \mathrm{~s}$ at the initial stage of oxidation of iron sulfide pellets, and that the reaction of mass decrease accompanied by the evolution of $\mathrm{SO}_{2}$ gas took place on the pellet surface at the subsequent stage, while the reaction of mass increase simultaneously proceeded in the inner part of the pellet. The rate of oxidation was controlled by the diffusional processes of oxygen in the pellet. 


\section{Nomenclature}

$a_{\mathrm{Fe}}$ : iron activity in sulfide, [-]

$c_{\mathrm{Fe}}$ : iron concentration, $\left[\mathrm{mol} \cdot \mathrm{m}^{-3}\right]$

$c_{\mathrm{SO}_{2}}: \mathrm{SO}_{2}$ concentration, [vol \%]

$d$ : pellet diameter, $[\mathrm{m}]$

$D_{\mathrm{e}}$ : effective diffusivity, $\left[\mathrm{m}^{2} \cdot \mathrm{s}^{-1}\right]$

$D_{\mathrm{Fe}}^{*}$ : self-diffusivity of iron, $\left[\mathrm{m}^{2} \cdot \mathrm{s}^{-1}\right]$

$D_{\mathrm{K}}$ : Knudsen diffusivity, $\left[\mathrm{m}^{2} \cdot \mathrm{s}^{-1}\right]$

$D_{\mathrm{O}_{2}}$ : molecular diffusivity of oxygen, $\left[\mathrm{m}^{2} \cdot \mathrm{s}^{-1}\right]$

$J_{\mathrm{O}_{2}\left(z=z_{\mathrm{i}}\right.}:$ rate of oxygen supply to interface, $\left[\mathrm{mol} \cdot \mathrm{s}^{-1}\right]$

$k_{\mathrm{g}}$ : mass transfer coefficient, $\left[\mathrm{m} \cdot \mathrm{s}^{-1}\right]$

$M_{i}$ : molecular mass of species $i$ $\left(i=\mathrm{O}_{2}, \mathrm{~N}_{2}, \mathrm{FeS}\right.$ and $\mathrm{Fe}_{0.90} \mathrm{~S}$ ), $\left[\mathrm{kg} \cdot \mathrm{mol}^{-1}\right]$

$n_{\mathrm{O}_{2}}$ : oxygen consumption due to reaction (12), $\left[\mathrm{mol} \cdot \mathrm{m}^{-3} \cdot \mathrm{s}^{-1}\right]$

$N_{i}$ : atomic fraction of $i(i=\mathrm{Fe}$ and $\mathrm{S}),[-]$

$p_{\mathrm{O}_{2}}$ : oxygen partial pressure, $[\mathrm{Pa}]$

$p_{\mathrm{O}_{2}}^{\mathrm{b}}: p_{\mathrm{O}_{2}}$ in bulk gas stream, $[\mathrm{Pa}]$

$p_{\mathrm{O}_{2}}^{\mathrm{s}}: p_{\mathrm{O}_{2}}$ at pellet surface, [Pa]

$r$ : radial distance in a particle, [m]

$r_{\mathrm{e}}$ : mean pore radius, $[\mathrm{m}]$

$r_{0}:$ radius of particle, [m]

$R$ : gas constant $(=8.314)$,

$$
\left[\mathrm{Pa} \cdot \mathrm{m}^{3} \cdot \mathrm{mol}^{-1} \cdot \mathrm{K}^{-1}\right]
$$

Re: Reynolds number, [-]

Sc: Schmidt number, [-]

$S h$ : Sherwood number, [-]

$t:$ time, [s]

$T$ : temperature, $[\mathrm{K}]$

$v$ : gas flow rate, $\left[\mathrm{m}^{3} \cdot \mathrm{s}^{-1}\right]$

$\Delta w$ : mass change of a particle, $[\mathrm{kg}]$
$\Delta W$ : mass change of pellet per unit surface area, $\left[\mathrm{kg} \cdot \mathrm{m}^{-2}\right]$

$y_{\mathrm{O}_{2}}$ : mole fraction of oxygen, [-]

$z$ : radial distance in pellet, $[\mathrm{m}]$

$z_{\mathrm{i}}$ : radius of interface, [m]

$z_{0}:$ radius of pellet, $[\mathrm{m}]$

$\varepsilon$ : porosity of pellet, $[-]$

$\varepsilon_{\mathrm{h}}$ : porosity of $\mathrm{Fe}_{2} \mathrm{O}_{3}$ layer, [-]

$\rho_{i}$ : density of species $i$ $\left(i=\mathrm{Fe}_{1.00} \mathrm{~S}\right.$ and $\left.\mathrm{Fe}_{0.90} \mathrm{~S}\right),\left[\mathrm{kg} \cdot \mathrm{m}^{-3}\right]$

$\eta_{i}$ : fractional resistance, $[-]$

$i=1$ : gas film mass transfer

$i=2$ : gas diffusion through oxide layer

\section{REFERENCES}

(1) Z. Asaki, K. Matsumoto, T. Tanabe and Y. Kondo: Met. Trans. B, 14B (1983), 109.

(2) T. A. Henderson: Trans. Inst. Min. Metall., 67 (1958), 497.

(3) W. Burgmann, G. Urbain and M. G. Frohberg: Memoires Sci. Rev. Met., 65 (1968), 567.

(4) H. Tsukada, Z. Asaki, T. Tanabe and Y. Kondo: Met. Trans. B, 12B (1981), 603.

(5) H. Haraldsen: Z. Anorg. Chem., 246 (1941), 169.

(6) E. T. Turkdogan: Trans. TMS-AIME, 242 (1968), 1665 .

(7) R. H. Condit: PhD Thesis, Physical Chemistry, Princeton univ., 1960.

(8) W. E. Ranz and W. R. Marshall, Jr.: Chem. Eng. Progr., 48 (1952), 173.

(9) N. Wakao and J. M. Smith: Chem. Eng. Sci., 17 (1962), 825.

(10) G. H. Geiger and D. R. Poilier: Transport Phenomena in Metallurgy, Addison-Wesley Publishing Co., California, (1973), p. 469.

(11) R. B. Bird, W. E. Stewart and E. N. Lightfoot: Transport Phenomena, John Wiley and Sons, Inc., New York (1960), p. 510. 